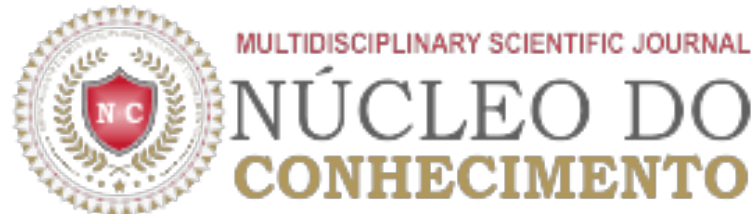

\section{A Contabilidade Pública como Ferramenta de Gestão no Enfrentamento da Crise Financeira}

\section{ARTIGO ORIGINAL}

DANTAS, Luiz Antônio de Oliveira [1], CALVO, Janaina Macedo [2]

DANTAS, Luiz Antônio de Oliveira; CALVO, Janaina Macedo. A Contabilidade Pública como Ferramenta de Gestão no Enfrentamento da Crise Financeira. Revista Científica Multidisciplinar Núcleo do Conhecimento. Edição 06. Ano 02, Vol. 01. pp 512-532, Setembro de 2017. ISSN:2448-0959

\section{RESUMO}

O Brasil vive uma crise econômica e financeira como há muito tempo não era observado. A irresponsabilidade de governantes causou um déficit de R \$ 139 bilhões em 2016 e dados recentes mostram que o problema de gestão interna foi o grande responsável pelos números negativos que impactou a sociedade. Estima-se que, nesse mesmo ano, o desemprego tenha atingido 12 milhões de brasileiros. O objetivo deste artigo é evidenciar que a contabilidade, usada como forma estratégica, tem potencial para auxiliar diretamente o Brasil na superação deste cenário negativo. Para isso, utilizou-se da literatura para mostrar a contabilidade pública, as ferramentas na gestão contábil e como estas podem auxiliar diretamente na superação da crise econômica e financeira. Conclui-se que, o fornecimento de informações por meio de relatórios fidedignos e transparentes, seja a melhor forma para auxiliar as tomadas de decisões usando os dados obtidos como ferramenta estratégica.

Palavras-chaves: Contabilidade Pública, Enfrentamento da Crise, Transparência, Informação Contábil.

\section{INTRODUÇÃO}

Quando se iniciou a execução deste material no início do ano de 2016, não se sabia ao certo como iria desenrolar o cenário econômico e político do Brasil. Este ano certamente foi atípico no contexto político nacional, o que impactou diretamente sobre os resultados de desempenho econômico, responsável por atingir todas as esferas da sociedade.

Alguns países com economia em expansão mostraram instabilidade, principalmente pelo grande número 
de agentes especuladores que fazem tomadas de decisões com base no nível de confiança, trabalham constantemente ligados às decisões políticas e aos fatores múltiplos que afetam a qualidade da mão de obra, do investimento em educação, da infraestrutura dentre outros.

Assim, pode-se compreender que a crise que o Brasil apresenta agora é resultado da crise mundial iniciada em 2007 e ao despreparo dos líderes para lidar com um cenário instável. Além disso, o alto índice de corrupção, a falta de mão de obra especializada, a crise política interna, a falta de estrutura etc. impulsionaram diretamente o cenário de crise acentuada que se identifica hoje. No entanto, mesmo sendo um assunto que merece atenção especial, este artigo não traz, como enfoque principal, os motivos que culminaram a crise econômica e política já instaurada, agora com novas expectativas após o impeachment, mas sim as ferramentas que podem ser usadas como estratégias para enfrentamento da crise.

\subsection{OBJETIVO}

Este artigo tem por objetivo principal analisar e enxergar, na contabilidade pública, um grande potencial que é identificar e ressaltar o potencial enfrentamento estratégico se aplicar a gestão contábil com liderança, estratégia e controle.

\subsection{JUSTIFICATIVA}

Justifica-se este artigo pela contribuição que ele poderá gerar para um melhor conhecimento do provável impacto com a adoção das normas e técnicas da contabilidade pública com uma gestão contábil voltada para liderança, estratégia e controle. Pretende-se aqui, abordar temas que possam influenciar nas tomadas de decisões, alterando, de alguma forma, a expectativa do resultado das instituições, sabendo-se que o resultado poderá ser impactado por diversos fatores não contábeis, como a influência das economias internacionais, o cenário nacional econômico e político, entre outros.

De acordo com o Conselho Federal de Contabilidade, por meio da NBC T 16.22 - Patrimônio e Sistemas Contábeis (2012, p. 10):

O sistema contábil representa a estrutura de informações sobre identificação, mensuração, avaliação, registro, controle e evidenciação dos atos e dos fatos da gestão do patrimônio público, com o objetivo de orientar e suprir o processo de decisão, a prestação de contas e a instrumentalização do controle social.

Estas normas estabelecem uma definição e classificam os elementos patrimoniais sob o aspecto contábil do patrimônio público e as informações contábeis necessárias para a evidenciação dos atos e fatos da gestão pública, contábil e transparência das tomadas de decisões.

Os dados encontrados servirão para subsidiar as reflexões de como a contabilidade pública, quando utilizada sob um "novo viés" e/ou viés além do que se reconhece como tradicional, pode impactar de forma positiva o cenário de crise acentuada que o Brasil enfrenta, além das decisões de um novo governo.

\section{REVISÃO DA LITERATURA}

\subsection{PRINCÍPIO DA ORGANIZAÇÃO EM SOCIEDADE GOVERNAMENTAL}


Antes de compreender a contabilidade pública em seu contexto contemporâneo, é preciso fazer uma pausa e retornar ao tempo para compreender que, a partir do momento que o homem passou a se organizar em sociedade, houve a necessidade de mecanismos reguladores de convivência, estruturados na forma de governo, que encontraram, na Administração Pública, subsídios para gerir a complexidade de uma sociedade e uma das bases complexas está relacionada diretamente à necessidade de criação e manutenção do espaço e de serviços públicos.

Segundo Augustinho e Oliveira (2014), para que seja possível viabilizar essa organização fez-se fundamental a tributação e, consequentemente, a contabilização desta quantidade por meio do que se reconhece como contabilidade pública.

Além disso, para o setor privado a contabilidade é tão importante quanto a capacidade de gerar lucros, pois é por meio da contabilidade e dos dados contábeis que os ganhos são calculados, projetados e as perdas reduzidas. Para o setor público a dimensão do potencial da contabilidade não é menor, pois é também por meio da contabilidade que se contabilizam ganhos e perdas da nação, bem como onde esses ativos serão aplicados, atingindo direta e indiretamente a vida de toda a sociedade, não apenas local, mas em uma conjunção global, mesmo que, nesta segunda, o impacto pareça menor.

Nas sociedades em desenvolvimento como é o caso do Brasil, a contabilidade pública toma importância fundamental no processo de desenvolvimento, pois é a contabilidade pública e a ação desenhada pelo planejamento governamental, que servirão como instrumento norteador. Além disso, de acordo com Augustinho e Oliveira (2014), a contabilidade também trará transparência nas aplicações dos recursos públicos, que atingirá diretamente a confiança por parte de investidores e parcerias entre países.

Haddad e Mota (2010) reforçam essas afirmações, mesmo de forma indireta, de que a contabilidade pública ou contabilidade aplicada à gestão pública é responsável pelo controle e orçamento do Patrimônio Público, existente desde a antiguidade como base de organização dos governos.

Augustinho e Oliveira (2014) reforçam a ideia de controle exercido pela contabilidade pública, explicando que as ações governamentais, quando transformadas em números, refletem nas demonstrações contábeis que, com o tempo se tornou ferramenta de controle social.

\subsection{CONCEITUANDO A CONTABILIDADE PÚBLICA}

Para o Conselho Federal de Contabilidade (2009, p. 27):

Contabilidade pública e? o ramo da ciência contábil que aplica, no processo gerador de informações, os princípios e as normas contábeis. Além disso, coleta, registra e controla os atos e fatos de natureza patrimonial, orçamentária e financeira do patrimônio público, evidenciando as variações e os consequentes resultados, inclusive sociais, nas entidades de administração pública e a elas equiparadas, proporcionando aos interessados, informações relevantes em apoio aos processos de tomada de decisão e de prestação de contas.

Contudo, a informação do próprio conceito e definição do Conselho Federal de Contabilidade (2009) é responsável por fornecer subsídio para se compreender a contabilidade pública como um instrumento de 
controle, ferramenta de transparência de informação contábil, responsável pela produção de relatórios que sirvam à administração no processo de tomadas de decisões, assim como nas instituições privadas.

Todavia compreende-se assim, que uma contabilidade mal executada, pode ser responsável por impactos desastrosos em uma sociedade. Daí alguns estudos que criticam a contabilidade criativa que, de certa forma, mascaram os dados reais e, consequentemente afirmam que as tomadas de decisões são baseadas em dados errôneos, o que pode ser um dos motivos que fizeram o Brasil chegar neste patamar de crise.

\subsection{IMPORTÂNCIA DA CONTABILIDADE PÚBLICA FRENTE À INTERNACIONALIZAÇÃO}

Outra preocupação que pode ser observada é a importância da Contabilidade Pública em atender às expectativas do contexto nacional. Além disso, deve ser ferramenta não apenas de tomada de decisão, mas também de transparência.

Um dos principais instrumentos da contabilidade pública é o orçamento. Dentro do orçamento pode ser encontrada a temática principal deste artigo com relação a fatores intrínsecos e extrínsecos que afetam diretamente o papel da contabilidade no contexto de crise, segundo Haddad e Mota (2010, p. 16).

O orçamento não pode ser compreendido apenas em função do fator financeiro. $\mathrm{O}$ orçamento deve estar vinculado às atividades de planejamento. Na realidade, o orçamento é um modo de materializar um planejamento, ou seja, de estabelecer de forma discriminada, todas as fontes e aplicações do dinheiro.

Em 2013, o a Secretaria do Tesouro Nacional publicou uma cartilha que considerou como "Nova contabilidade pública". Nesta cartilha os organizadores - dentre eles o ministro do estado da fazenda na época, Guido Mantega - consideraram que a contabilidade brasileira está sendo influenciada diretamente pelos organismos internacionais por meio da adoção das normas internacionais de contabilidade.

Outro fator relevante e constante é o acompanhamento da contabilidade às normas internacionais que se deu justamente em 2008, pela Portaria n 184/2008, conforme Carvalho (2015). Nota-se que, se por um lado, o mundo eclodia em uma prévia crise econômica que viria afetar diretamente o contexto brasileiro, por outro lado, havia a preocupação de se adotarem ferramentas de controle e transparência que pudessem facilitar as tomadas de decisões necessárias na visão do ministro.

Porém, apesar de 2008 ter sido o ponto de partida, as normas não foram únicas, é necessário que a contabilidade, assim como as demais ciências sejam capazes de acompanhar as mudanças sociais. Desta forma, a Secretaria do Tesouro Nacional (STN) divulga, anualmente, o Manual de Contabilidade Aplicada ao Setor Público (MCASP) com base nas (International Public Sector Accounting Standards ou, em português, Normas Internacionais Aplicadas ao Setor Público) IPSAS e nas normas do Conselho Federal de Contabilidade (CFC), respeitando a legislação vigente.

\subsection{EVOLUÇÃO DA CONTABILIDADE PÚBLICA}

Convém lembrar que, a fim de mostrar as principais evoluções na contabilidade brasileira, o STN publicou uma sequência cronológica das evoluções contábeis identificadas no Brasil (Anexo I). Essas iniciativas implementadas após o ano de 2008, certamente foram um grande avanço para o Brasil e, pautar-se em mostrar e discutir essas implementações e evoluções dentro da contabilidade, certamente 
seria considerado o foco central deste artigo. No entanto, far-se-á elucidações daqui em diante apenas de alguns pontos que podem culminar para o desenvolvimento positivo deste estudo. De acordo com Augustinho e Oliveira (2014, p. 50), isso é possível ao se considerar que:

As interfaces do controle social dependem do acesso à informação e da mobilização e capacitação dos administrados, infere-se que, a contabilidade aplicada ao setor público, pode ser suporte de qualidade à instrumentalização do controle social, à medida que essas informações sejam compreensíveis e significativas para o cidadão, considerando o próprio conceito dado a essa expressão pela Norma Brasileira de Contabilidade Aplicada ao Setor (NBC T) 16.1, que define a instrumentalização do controle social como "o compromisso fundado na ética" profissional, que pressupõe o exercício cotidiano de fornecer informações que sejam compreensíveis e úteis aos cidadãos no desempenho de sua soberana atividade de controle do uso de recursos e patrimônio público pelos agentes públicos.

Porém, a tecnologia usada pela contabilidade pública deve ser uma ferramenta ao exercício da democracia e possibilitar e/ou viabilizar o exercício da contabilidade trabalhando para fins múltiplos.

O fim múltiplo que a contabilidade pode alcançar é estar diretamente relacionada à necessidade dos profissionais de contabilidade em usar os conhecimentos de outras áreas, especialmente aqueles aplicados à gestão de pessoas, ferramentas e posicionamentos estratégicos, enfim, outras funções que transpassam apenas a capacidade de trazer informação em relatórios e números, mas sim, usar estes, como embasadores de atitudes e ações pontuais.

\subsection{FERRAMENTAS DE GESTÃo CONTÁBIL}

Por outro lado, a contabilidade pública possui inúmeras ferramentas que possibilitam as tomadas de decisões e controle dentro do processo de gestão. No entanto, tem-se observado um maior número de possibilidades e ferramentas do que antes se achava possível. Esta afirmativa tem sido observada na construção de muitos estudos, conforme será mostrado no decorrer deste estudo.

Desta forma, buscando compreender as ferramentas de gestão contábil e/ou as ferramentas que a contabilidade pode proporcionar, tanto na abordagem epistemológica quanto em suas práxis e influência sobre o indivíduo que nela opera e/ou dela se utilizam nas informações, buscar-se-á neste estudo, discorrer sobre a contabilidade pública como ferramenta e suas concepções no contexto de liderança, estratégia e controle.

\subsubsection{CONTABILIDADE PÚBLICA COMO FERRAMENTA}

Conforme mencionado anteriormente, à contabilidade exerce influência na sociedade desde os primórdios. No entanto, o que de certa forma tem sido recente, são os estudos que apontam a contabilidade como ferramenta estratégica, principalmente, por sua capacidade de produzir informações assertivas. Para Augustinho e Oliveira (2014), isso ocorre, principalmente, porque líderes são pressionados a tomar decisões todos os dias e os relatórios são capazes de fornecer informações substanciais para essas tomadas de decisões.

$\mathrm{Na}$ administração pública não é diferente, devido à sua complexidade de impacto, pode-se dizer que os posicionamentos de líderes preocupados com as tomadas de decisões estratégicas podem subsidiar 
tomadas de decisões e, consequentemente, manter uma economia estável.

\subsubsection{LIDERANÇA}

Por muitos anos a liderança fez e ainda faz parte do interesse de estudos de muitos pesquisadores, sejam acadêmicos ou de mercado. Tal preocupação se dá pelo fato de que as organizações do governo ou privadas, com ou sem fins lucrativos, estão sujeitas aos resultados provenientes e/ou diretamente ligados a política de liderança.

Augustinho e Oliveira (2014) definem o líder em três categorias: estratégico, visionário e gerencial.

Embora não seja objetivo deste estudo desenvolver as peculiaridades que existem em cada tipo de líder, far-se-á uma breve conceituação, com base em Pereira (2015, p. 45), e seu estudo com foco especial no contexto de liderança estratégica. O Anexo II apresenta detalhes das três formas de liderança conceituadas e definidas pelo autor.

No caso da liderança dentro do setor público, seja ele, municipal, estadual ou federal, enfrentar desafios peculiares a outras formas de gestão, traz desafios peculiares aos líderes. Dentre os desafios encontrados está o fato de que a estabilidade de emprego exercida pela maioria dos servidores traz um cenário desfavorável aos líderes em tomadas de decisões e alcance por resultados rápido, cabendo ao líder, o desafio de adequar seu estilo de liderança de acordo com a realidade local de forma a buscar o melhor desempenho possível.

Segundo Rowe (2002, p. 18):

Lidar com o paradoxo de liderar e gerenciar são difíceis, mas é possível para uma massa crítica em organizações que não perderam o controle estratégico. Os executivos dessas organizações devem começar a ver-se como líderes estratégicos que necessitam aceitar e unir líderes visionários e gerenciais. Devem combater as influências coercitivas do controle financeiro e lutar pelo exercício dos controles estratégicos e financeiros, com ênfase nos estratégicos. Devem entender os conceitos de conhecimento tácito e explícito, de pensamento linear e não linear e perceber como podem integrá-los para que a organização se beneficie. As recompensas, frequentemente, serão a criação de valor e a performance superior à média tanto nas organizações recém-criadas como nas já estabelecidas.

De acordo com Augustinho e Oliveira (2014), é possível compreender que houve uma exigência externa, que pressionou o contexto público a adotar padrões que aperfeiçoavam os resultados de organizações internacionais. Porém, este cenário impulsionou os gestores públicos a se tornarem lideres públicos e a desempenharem resultados, mesmo que o cenário seja diferente dos desafios de um líder do setor privado.

\subsubsection{ESTRATÉGIA}

Outro fator existente é que a gestão pública está introduzida em uma esfera multifacetada e é imprescindível que a estratégia se faça independente do setor em que se atue.

Segundo Oliveira (2012, p. 27): 
A estratégia de ação deve ser mais bem elaborada e conjuntos de alternativas devem ser apresentados e defendidos, debatidos e amplamente discutidos. E isso leva tempo, o líder político, a quem cabe à defesa dos interesses da sociedade, deve entender esse ambiente complexo, essa miscelânea de interesses, para tomar suas decisões, defender seus objetivos e buscar as concretizações de suas metas. Essas mesmas decisões, defesa de objetivos e interesse e concretização de metas não ficam somente a níveis estratégicos das organizações ou a níveis políticos.

O Conselho Regional de Contabilidade do Rio de Janeiro realizou, em 2015, promoveu uma discussão sobre a importância de práticas de liderança na contabilidade aplicada ao setor público. Essa discussão foi realizada porque quando se fala em contabilidade no setor público deve-se atuar com liderança na capacitação de formas de demonstração dos dados e captação de informações para traçar um cenário de previsão analítico e com responsabilidade do futuro, sem que haja qualquer tipo de corrupção utilizando ferramentas que a contabilidade permita, ou seja, liderança e estratégia com responsabilidade.

De acordo com Oliveira e Soares (2010, p. 13):

Fatores exógenos, tais como a globalização da economia e a evolução tecnológica passaram a exigir a modernização do aparelho do Estado, a descentralização de funções e o fortalecimento da capacidade de governo para desempenho do seu papel estratégico na promoção do desenvolvimento econômico e social. Para tal, um Estado gerencialmente competente, com estruturas ágeis e capazes de dar respostas às demandas da sociedade, tornava-se uma necessidade. Além disso, transformações de ordem econômica e organizacional, associadas à democracia e uma maior consciência de cidadania deram margem a demandas por participação e transparência na condução dos gastos públicos. Começaram a ser observados exemplos de corrupção, em diversos níveis, que colocaram em questionamento a eficácia dos instrumentos formais de controle, reinantes no modelo burocrático.

Já a Secretaria do Tesouro Nacional (2016) em parceria com o Conselho de Federal alude ainda que, a contabilidade contemporânea tem funções amplificadas e que, nessas funções, a liderança toma um papel importante, conforme pode ser visto na Figura 1.

A Figura 1 mostra, de forma clara, que a gestão contábil que atende à demanda contemporânea da internacionalização e que visa garantir o sucesso do setor ou da esfera em que atua, deve ter uma liderança que vislumbre a contabilidade como um todo, e que inclua uma visão globalizada de futuro. Além da liderança, também é necessário, na gestão contábil, trabalhar em cima de controle, como será tratado na sequência deste estudo. 


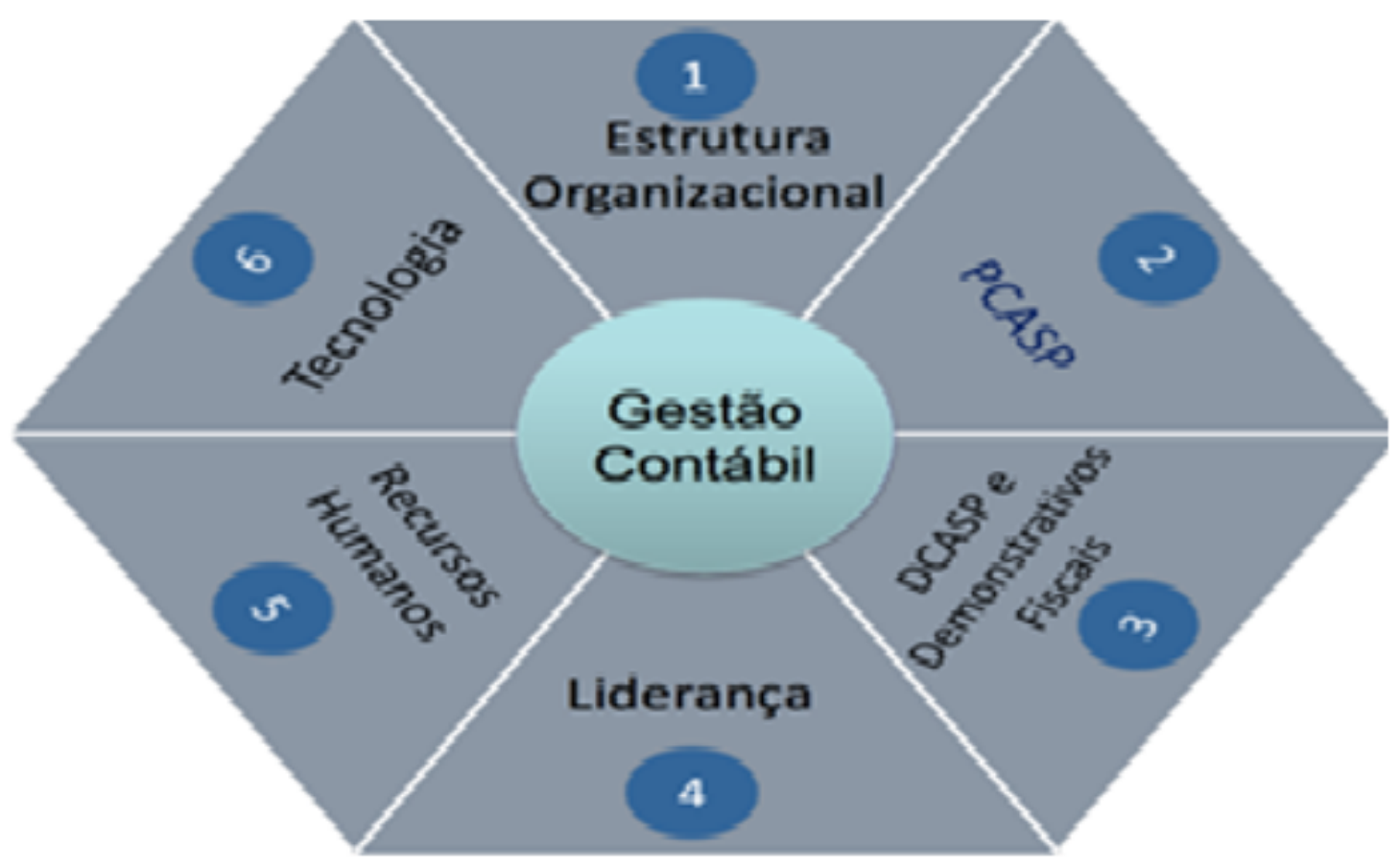

Proposta da Nova Gestão Contábil. Fonte: Feijó, 2012.

Figura $1-$

\subsubsection{CONTROLE}

Da mesma forma, o controle na gestão pública, incluindo a contabilidade é um dos assuntos mais discutidos por pesquisadores, estudiosos e profissionais. Tal preocupação se dá especialmente pelo fato do controle ser um dos principais desafios dentro do setor público e, deste controle, depende diretamente o fracasso e o sucesso da gestão.

Oliveira e Soares (2010) se dedicaram em estudar a importância e formas de controle na gestão pública e trouxeram contribuições importantes no contexto de controle.

Concorda-se que, o controle exerce função sistêmica e, portanto, fundamental para as organizações, sejam elas públicas ou privadas. O controle na administração pública deve ser exercido de forma interna e externa. Além disso, o controle no contexto da contabilidade servirá como base para tomadas de decisões, como se tem mostrado no decorrer deste estudo.

\subsection{ENFRENTAMENTO DA CRISE POR MEIO DA CONTABILIDADE PÚBLICA}

A ideia de crise certamente traz rumores de incertezas para o mercado, principalmente, quando a crise é dual (política e econômica), fazendo com que investidores logo passem a uma postura de retenção. Como já mencionado anteriormente, são as economias em desenvolvimento que dependem diretamente da confiança de investidores para continuar crescendo, cenários de incertezas fazem com que, grupos de investidores e até mesmo países aliados, retirem-se até que o cenário melhore. 
Sabe-se que, as agências de investimentos internacionais são atores fundamentais no processo de investimento, pois analisam o cenário econômico e político de um país trazendo, aos investidores, pareceres favoráveis ou não para o desenvolvimento. São ferramentas importantes para os países com economias crescentes como o Brasil. No entanto, no ano de 2015 e início de 2016, o Brasil foi rebaixado pelas três maiores agências de investimento: a Fitch, a Moody`s e a S\&P.

Com isso, a crise financeira atinge diretamente a organização social como um todo, pois sociedades declaradas capitalistas dependem do capital financeiro para a própria subsistência. Assim, far-se-á uma breve elucidação sobre este contexto para deixar ainda mais evidente a necessidade de recuperação da crise financeira no Brasil.

É do conhecimento de todos que a crise econômica que vem se alastrando pelo mundo desde 2008 e se instalando no Brasil, teve seu impacto impulsionado pela corrupção, pela falta de gestão, controle e compromisso com os impactos que poderiam surgir.

Bispo et al. (2009, p. 11), argumentam que:

A recessão atual e? diferente das anteriores. Além da dimensão global, a crise destruiu trilhões de dólares em ativos financeiros, afetando empresas e famílias. Os investimentos privados somente retornarão quando os níveis de atividade ocupar uma grande capacidade instalada, hoje ociosa, e os níveis de consumo das famílias somente voltarão a? normalidade depois da recuperação dos empregos, da renda e dos altos níveis de endividamento.

Nota-se ainda que, estas elucidações, foram retiradas de um manual que, já em 2009, reunira muitos especialistas que, na época, estavam já identificando os respingos da crise econômica mundial no Brasil, e alertando para o endividamento das famílias e desempregos. No entanto, os especialistas não imaginavam que o quadro se agravaria, pelo menos dez vezes mais, ao ser identificado grande desvios nas operações da Polícia Federal. Faz-se necessário então compreender a trajetória de como a crise se instalou no Brasil.

\subsubsection{A CRISE E SUA TRAJETÓRIA}

De acordo com Bispo et al. (2009) a crise financeira no Brasil começou com o reflexo da crise americana de 2008, sendo inicialmente implementada pela ausência de manifestação e ações do governo sobre o assunto. Na época, os governantes se mostravam otimistas e diziam que a crise não chegaria ao contexto brasileiro, mas que, caso chegassem, medidas seriam tomadas. No entanto, de acordo com os governantes daquela época, o Brasil não devia tomar nenhum tipo de ação precatória já que não seria atingido.

Infelizmente, o cenário sequente a essas declarações mostrou que o Brasil viveria uma avalanche, que não só traria uma crise econômica, calculada por alguns especialistas, como a pior crise dos últimos 30 anos, mas também, uma crise política que levaria a queda da ex-presidente Dilma Rousseff.

O artigo publicado por Mendonça (2016, p. 8) na revista Carta Conjuntura, trata com louvor os motivos e resultados da crise econômica no país. Dentre as elucidações do autor destaca-se o déficit do fechamento do ano de 2015:

Com isso, o déficit primário do setor público consolidado fechou em $\mathrm{R} \$ 106,95$ bilhões, equivalente a 
$1,9 \%$ do produto interno bruto (PIB). Para este ano, a meta de resultado primário foi inicialmente estabelecida pela Lei de Diretrizes Orçamentárias (LDO) em R \$ 30,554 bilhões (equivalente a 0,5\% do PIB), sendo R \$ 24 bilhões a cargo da União.

É também necessário ressaltar que as operações que revelaram grandes esquemas de corrupção em todos os setores do Brasil, especialmente na Petrobrás, foram responsáveis por diminuir os investimentos no Brasil, desta forma, além de diminuição na coleta dos tributos, o Brasil ainda está tendo que enfrentar o desemprego.

O Gráfico 1 mostra o quociente entre os resultados do setor público e o PIB acumulado entre os anos de 2013 e 2016. O Gráfico 1 mostra também que é possível compreender que o déficit financeiro do país caiu de forma desastrosa nos últimos três anos. Mendonça (2016) ainda achou arriscado prever sobre a execução orçamentária deste ano. No entanto, observa-se que a previsão para este ano parece não apontar reflexos de melhorias imediatas.

Mesmo assim, ainda é cedo para falar em superação da crise econômica. O Brasil fecha com um déficit de $\mathrm{R} \$ 139$ bilhões nas contas públicas e, até o momento, 12 milhões de desempregos foram contabilizados. No entanto, com a saída da ex-presidente Dilma Rousseff por meio do impeachment e a ocupação do cargo presidencial pelo seu sucessor, Michel Temer, alguns especialistas já começam a apontar graus de melhorias para o futuro do Brasil.

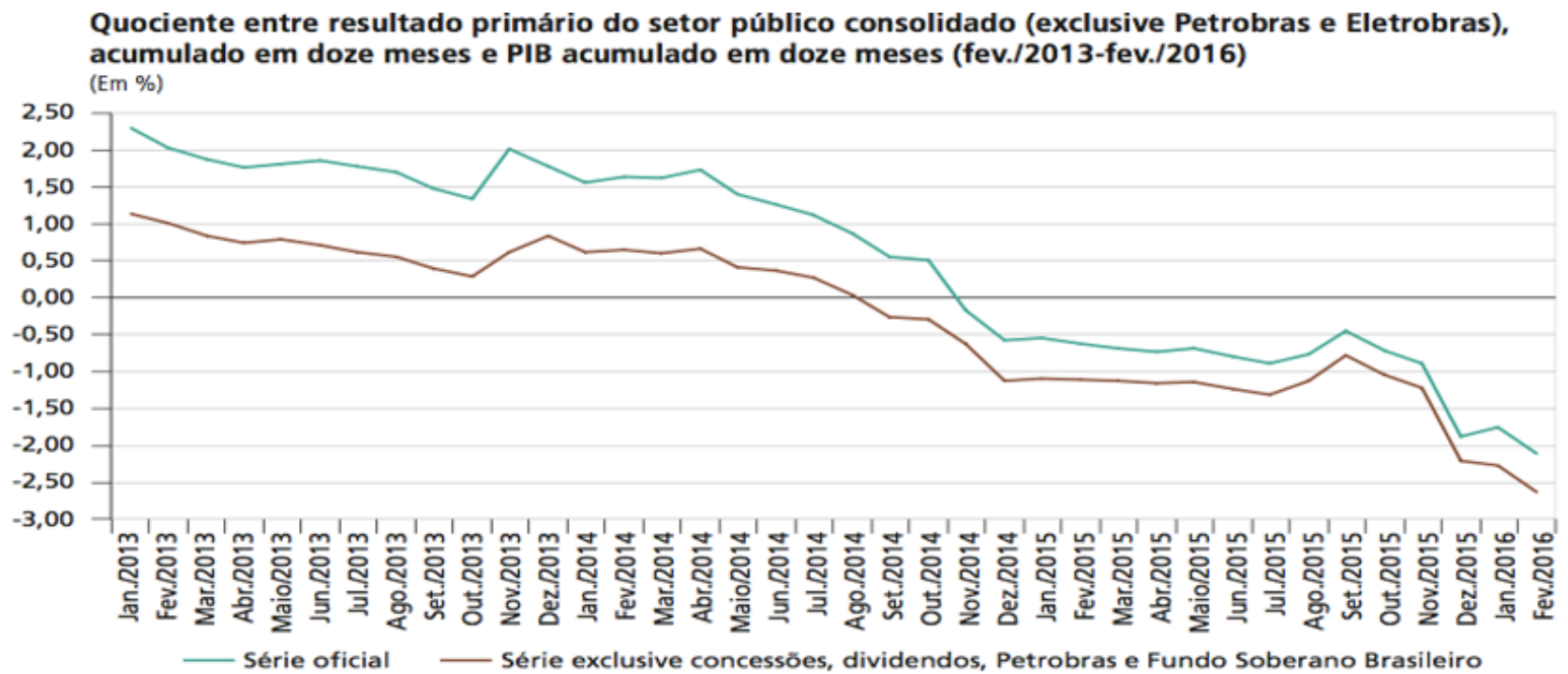

Gráfico 1 - Resultado primário do setor público. Fonte: Mendonça, 2016.

A contabilidade pública aparece como uma das possibilidades mais presentes no contexto brasileiro, mesmo porque um dos quadros que mais agravaram a crise contemporânea foi à falta de informação concreta e transparente nos relatórios contábeis. Sabendo-se que os usuários da contabilidade pública são os cidadãos, os membros do legislativo, os investigadores e os credores que emprestam recursos ou que participam no processo de financiamento.

Não obstante, para atendimento desses usuários são idealizados relatórios que devem ser apresentados de 
forma transparente e da forma mais inteligível possível, deixando claro que as contribuições devem ocorrer dentro do controle, da liderança e da estratégia.

É possível compreender também a necessidade de uma liderança contábil eficiente, capacitada a atuar como ferramenta estratégica e de um controle mais efetivo e duradouro. Além destas, existem, segundo Oliveira, Sant'Anna e Vaz (2010, p. 1.468), as competências requeridas ao gestor público brasileiro contemporâneo, de acordo com o Anexo III.

\section{PROCEDIMENTOS METODOLÓGICOS}

Com relação às pesquisas exploratórias e descritivas, Gil (2010, p. 27) afirma:

As pesquisas exploratórias têm como propósito proporcionar maior familiaridade com o problema, com vistas a torná-lo mais explícito ou a construir hipóteses. Seu planejamento tende a ser bastante flexível, pois interessa considerar os mais variados aspectos relativos ao fato ou fenômeno estudado. A coleta de dados pode ocorrer de diversas maneiras, mas geralmente envolve o levantamento bibliográfico.

As pesquisas descritivas têm como objetivo a descrição das características de determinada população.

Para o estudo e análise deste artigo, buscou-se, por meio de levantamentos bibliográficos realizados durante o período de fevereiro de 2016 até janeiro de 2017, aqueles que pudessem subsidiar os objetivos desta pesquisa, se destacando pelos vieses descritivos e exploratórios, a fim de que a questão analisada fosse elucidada em todos os seus aspectos.

No entanto, a análise desenvolvida foi feita a partir das especificidades de cada conceito e estudos práticos, levando-se em consideração a relevância do tema, utilizando-se ainda a comparabilidade qualitativa em casos específicos e os reflexos de economias distintas. Já a natureza deste estudo é a básica empírica.

\section{ANÁLISE DOS RESULTADOS}

Algumas ações dentro da contabilidade podem ser consideradas fundamentais no processo de enfrentamento, são elas: qualidade dos relatórios contábeis, liderança estratégica, controle e meios de controle, transparência e uso de tecnologia da informação.

Essas são as principais ações que visam oferecer subsídios para que a contabilidade possa servir como ferramenta estratégica direta, não apenas para enfrentamento da crise, mas também para que haja uma continuidade da saúde financeira e um alto e constante desenvolvimento de um país. Concordando com Augustinho e Oliveira (2014, p. 65):

Percebe-se, também, que apenas compreender a terminologia básica da contabilidade não é suficiente para se conhecer a realidade da gestão dos recursos públicos. Faz-se necessário que os resultados sejam contextualizados e esclarecidos por meio da análise e da interpretação dos relatórios contábeis e apresentados em uma linguagem acessível à compreensão do cidadão.

\section{CONSIDERAÇÕES FINAIS}


O presente estudo teve origem no interesse em investigar a contabilidade pública como ferramenta estratégica para o enfrentamento da crise. No decorrer de sua construção, foi possível observar que as economias de países em desenvolvimento são reconhecidamente frágeis e dependentes diretas das decisões políticas e do equilíbrio do controle financeiro.

Por outro lado, a contabilidade pública, neste contexto, mostra-se fundamental, principalmente a contabilidade de controle, sendo esta, responsável tanto pelas decisões internas do país quanto pela responsabilidade de fornecer informações que possam estabelecer o grau de saúde econômica e, consequentemente, trazer investimentos externos.

Como limitação deste estudo, não foi considerada a influência política nas tomadas de decisões dentre outras variáveis que possam afetar o desempenho e a economia. Sugere-se que outros estudos que se preocupem em dimensionar a aplicação da contabilidade sejam realizados, principalmente estudos que possam trazer contribuições para que a contabilidade pública auxilie o desenvolvimento econômico do país.

Foi observado neste artigo que, qualquer atividade, assim como a gestão pública, necessita de instrumentos estratégicos para melhor gerenciamento dos recursos para seu pleno desenvolvimento. Sendo assim, afirma-se que os instrumentos contábeis se constituem como necessários e preponderantes para o controle, projeção, planejamento do futuro enfrentamento da crise, como um todo e como base fundamental para uma contabilidade saudável e um país mais justo e verdadeiro.

\section{REFERÊNCIAS}

AUGUSTINHO S. M.; OLIVEIRA, A. G. Informação contábil pública como instrumento de controle social: A percepção de líderes comunitários na cidade de Curitiba. RIC - Revista de Informação Contábil, v. 8, n. 2, p. 49-68, abr.-jun., 2014.

BISPO, C. R.; MUSSE, J. S.; VAZ, F. T.; MARTINS, F. J. M. (Org.). Crise financeira mundial: Impactos sociais e no mercado de trabalho. Associação Nacional dos Auditores Fiscais da Receita Federal do Brasil - ANFIP. Brasília: ANFIP, 2009, 200p.

CARVALHO, J. Contabilidade aplicada ao setor público: Normas brasileiras de contabilidade aplicadas ao setor público - NBC T ASP 16. Conselho Regional de Contabilidade, 2015.

CONSELHO Federal de Contabilidade. Manual de contabilidade do sistema CFC/CRCs. Brasília: CFC, 2009.

FEIJÓ, P. H. A consolidação das NBCT SP no Brasil: Cronograma de Implantação. II Fórum Nacional de Contabilidade Pública. 19 CBC-ago., 2012.

GIL, A. C. Como elaborar projetos de pesquisa. 5. ed. São Paulo: Atlas, 2010.

HADDAD, R. C.; MOTA, F. G. DE L. Contabilidade pública. Florianópolis: Departamento de Ciências da Administração da Universidade Federal de Santa Catarina (UFSC). Brasília: CAPES-UAB, 2010. 
MENDONÇA, M. A. A. Finanças públicas. Carta de conjuntura, n. 30, mar., 2016.

OLIVEIRA, F. B.; SANT’ANNA, A. S.; VAZ, S. L. Liderança no contexto da nova administração pública: Uma análise sob a perspectiva de gestores públicos da Minas Gerais e Rio de Janeiro. RAP Revista de Administração Pública, v. 44, n. 6, pp. 1453-75, Rio de Janeiro, nov./dez., 2010.

OLIVEIRA, J. A. FILHO; SOARES, A. F. Controle interno e externo da gestão pública. Curso de PósGraduação, WPos, 2010.

OLIVEIRA, T. F. Desafio do exercício da liderança em organizações públicas: Uma análise na Secretaria de Estado da Fazenda do Rio Grande do Sul. Porto Alegre: Escola de Administração da Universidade Federal do Rio Grande do Sul (UFRGS), 2012.

PEREIRA, M. M. Liderança estratégica como diferencial competitivo nas empresas. Lisboa: Instituto Politécnico de Lisboa, Instituto Superior de Contabilidade e Administração de Lisboa (ISCAL), 2015.

ROWE, W. G. Liderança estratégica e criação de valor. ERA - Revista de Administração de Empresas, v. 42, n. 1, pp. 7-19, jan./mar., 2002.

SECRETARIA do Tesouro Nacional. Cartilha e manual de contabilidade, 2016. Disponível em: <http://www.fazenda.sp.gov.br/ipsas/cartilha.pdf>. Acesso em ago., 2016. 


\section{Evolução da Contabilidade Pública e Gestão Fiscal no Brasil.}

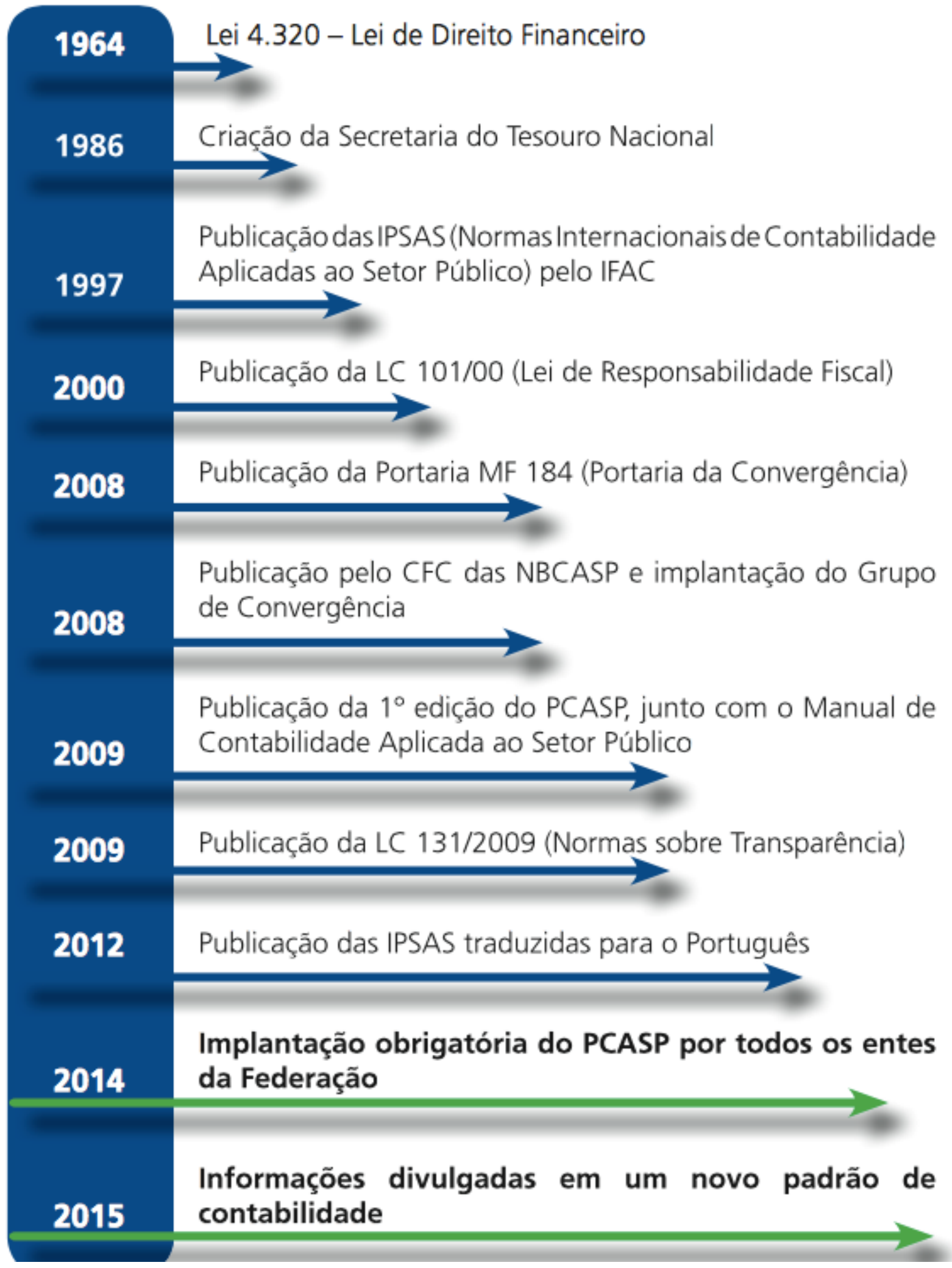

ANEXO I - Evolução da contabilidade pública e gestão físcal no Brasil. Fonte: SECRETARIA do Tesouro Nacional, 2016. 
Revista Científica Multidisciplinar Núcleo do Conhecimento - RC: 10891 - ISSN: 2448-0959

https://www.nucleodoconhecimento.com.br/contabilidade/contabilidade-publica

Quadro 1 - Liderança estratégica, visionária e gerencial

\begin{tabular}{|c|c|c|}
\hline Lideres estratégicos & is & ciais \\
\hline $\begin{array}{l}\text { - Usam padrōes de pensamento } \\
\text { linear e nāo linear } \\
\text { - Acreditam na adoção de } \\
\text { estratégias, isto é, suas decisōes } \\
\text { estratégicas fazem diferença em } \\
\text { suas organizações e ambiente } \\
\text { de trabalho }\end{array}$ &  & 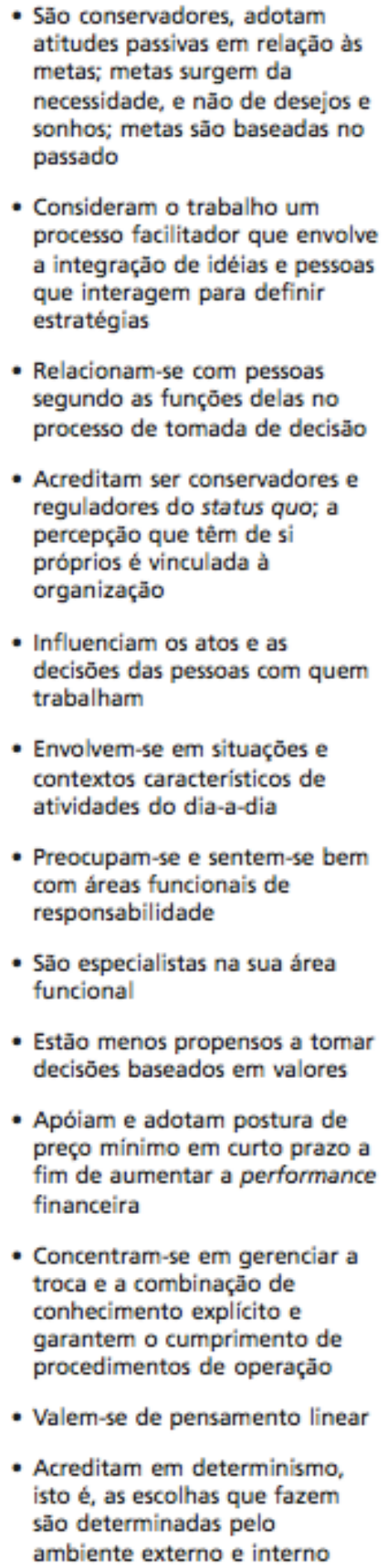 \\
\hline
\end{tabular}

Liderança estratégica, visionária e gerencial. Fonte: PEREIRA, 2015. 


\begin{tabular}{|c|c|}
\hline $\begin{array}{l}\text { Competências } \\
\text { requeridas ao } \\
\text { gestor público }\end{array}$ & Relatos \\
\hline $\begin{array}{l}\text { Conhecimento da } \\
\text { máquina pública }\end{array}$ & $\begin{array}{l}\text { "Assim, conhecimento de como funciona a máquina é importante Ele não precisa } \\
\text { ter trabalhado especificamente. Vamos supor, a pessoa năo precisa ter trabalhado } \\
\text { no estado, para desempenhar bem o papel de gestor no estado. Mas ela precisa ter } \\
\text { uma noçăo de como é que o jogo funciona em organizaçôes públicas do executivo." }\end{array}$ \\
\hline $\begin{array}{l}\text { Conhecimento } \\
\text { jurídico }\end{array}$ & $\begin{array}{l}\text { "Um segundo aspecto: infelizmente, é conhecer bem a parte legal. Porque o que } \\
\text { acaba acontecendo? A gente percebe essa dissociaçăo entre estado e sociedade, } \\
\text { e a sociedade não cobra. Entâo, outros meios começam a querer cobrar. E a } \\
\text { gente tem uma judicializaçăo imensa no estado, ninguém se preocupa em } \\
\text { saber se é importante comprar um calendário ou nâo é importante comprar um } \\
\text { calendário. Está todo mundo preocupado se o processo de compra de calendário } \\
\text { está obedecendo à lei, nas suas virgulas e nos seus pontos e virgulas." }\end{array}$ \\
\hline $\begin{array}{l}\text { Capacidade de } \\
\text { promover o } \\
\text { envolvimento da } \\
\text { sociedade }\end{array}$ & $\begin{array}{l}\text { "Com relação no sentido mais macro, eu vejo que seria conseguir o envolvimento } \\
\text { da sociedade, de forma estruturada. Eu acho que o maior desafio é fazer esse } \\
\text { processo bem feito, o que significaria ele ser irreversivel, mas ele ser organizado." }\end{array}$ \\
\hline $\begin{array}{l}\text { Capacidade de } \\
\text { lidar com o público }\end{array}$ & $\begin{array}{l}\text { "Por exemplo, na área de RH, o maior problema que a gente teve foi de } \\
\text { habilidade, eles não tinham habilidades de lidar com o público, porque eles } \\
\text { estão ali para atender as pessoas. Eles conheciam profundamente a matéria, a } \\
\text { legislação de recursos humanos, mas não tinham habilidade em lidar com aquilo, } \\
\text { que era o público, que era o usuário dele." }\end{array}$ \\
\hline Objetividade & $\begin{array}{l}\text { "Ele [o gestor público] deve ser extremamente objetivo. Eu acho que a pluralidade } \\
\text { de assuntos pode levar a desvios. Então, eu acho que ele precisa ser bastante } \\
\text { objetivo, ter uma meta e buscar atingir aquilo que ele deseja." }\end{array}$ \\
\hline $\begin{array}{l}\text { Orientaça para } \\
\text { resultados }\end{array}$ & $\begin{array}{l}\text { "Em outras palavras, o gestor que vai operar o estado, tem que ter em mente } \\
\text { que ele precisa atingir um resultado final. Ele tem que entender que ele é um } \\
\text { profissional que tem que apresentar um resultado, assim como é um profissional } \\
\text { do mercado. Então, o que eu vejo hoje que precisaria no setor público são as } \\
\text { pessoas mais preocupadas com o resultado e menos com os processos pelos } \\
\text { quais você alcança esse resultado." }\end{array}$ \\
\hline Perspectiva global & $\begin{array}{l}\text { "E assim, ele [o gestor público] tem que ser um gestor globalizado, ele tem que } \\
\text { estar sintonizado com as mudanças que estão ocorrendo, já que ele não pertence } \\
\text { mais ao estado, digamos assim, isoladamente. Mas, um estado que é conjunto de } \\
\text { uma Federação e muito mais federalizado do que nunca." }\end{array}$ \\
\hline $\begin{array}{l}\text { Relacionamento } \\
\text { interpessoal }\end{array}$ & $\begin{array}{l}\text { "E obviamente, em termos de habilidades assim, o interpessoal conta muito, } \\
\text { porque a nossa sociedade é muito relacionada. Então, tem que lidar, gerenciar o } \\
\text { pessoal, porque o seu pessoal é muito importante, até mesmo para trazé-los para } \\
\text { trabalhar junto." }\end{array}$ \\
\hline Visão sistêmica & $\begin{array}{l}\text { "Ou seja, um gerente, um lider, aqui na nossa administração, tem que ter uma } \\
\text { visăo sistêmica voltada, obviamente, para a situação do país, do mundo, mas } \\
\text { focado na área pública. Mas, eu não tenho dúvida de que um lider e um gestor } \\
\text { da iniciativa privada também tenham que ter uma visão sistêmica, mas, com foco } \\
\text { já no negócio dele, já na área privada dele. Agora, eu acho que a gente está se } \\
\text { assemelhando, cada vez mais, às competências requeridas para a área privada e } \\
\text { para a área pública, em nivel de gerente, de gestor, de liderança." }\end{array}$ \\
\hline
\end{tabular}
VAZ, 2010.

[1] Mestrando Profissional em Controladoria Empresarial pela Universidade Presbiteriana Mackenzie. Especialista (MBA) em Contabilidade Pública e Responsabilidade Fiscal pelo Centro Universitário Internacional. Graduado em Ciências Contábeis pela Fundação Escola de Comércio Alvares Penteado. Contador da Faculdade de Direito de São Bernardo do Campo. 
[2] Mestrado Profissional em Controladoria Empresarial pela Universidade Presbiteriana Mackenzie. Especialista (MBA Executivo) pela Brazilian Business School (BBS) com módulo internacional realizado em Luanda/Angola no Programa de Intercâmbio Internacional. Graduada em Economia pela Fundação Armando Álvares Penteado (FAAP) e Técnica Contábil pelo Colégio Osvaldo Cruz Paes Leme. Professora dos cursos de MBA da Fundação Getulio Vargas (FGV), Universidade Presbiteriana Mackenzie, Universidade Municipal de São Caetano do Sul (USCS), Universidade Estácio de Sá, Faculdade ENIAC e INPG Business School. Gerente de Contabilidade e Finanças do Conselho Regional de Engenharia e Agronomia (CREA/SP).

\section{PUBLIQUE SEU ARTIGO CIENTÍFICO EM:}

https://www.nucleodoconhecimento.com.br/enviar-artigo-cientifico-para-submissao 